\title{
PENINGKATAN PENGETAHUAN INTERVENSI DINI (EARLY INTERVENTION) BAHASA BICARA ANAK BERKEBUTUHAN KHUSUS MODEL LAYANAN AKOMODATIF
}

\author{
Ilham Akerda Edyyul ${ }^{1}$, Yuli Afmi Ropita Sari ${ }^{2}$, Anggawati Imanniyah ${ }^{3}$ \\ Prodi D III Terapi Wicara STIKes Mercubaktijaya Padang \\ E-mail korespondensi : ilhamakerdaedyyul@yahoo.com
}

Article History:
Received: 08 April 2021
Revised: 15 April 2021
Accepted: 10 Mei 2021
Kata Kunci : Bahasa bicara,
anak berkebutuhan khusus,
intervensi dini, layanan
okomodatif

Keywords: : Speech language, children with special needs, early intervention, accommodative services

\section{Abstrak:}

Latar belakang :Modal awal pola penanganan untuk anak berkebutuhan khusus karena memerlukan persiapan yang berbeda dengan anak normal pada umumnya. Melalui deteksi dini dan intervensi dini bahasa bicara anak-anak keberadaan tentang pola perkembangan yang berbeda dan mengarah pada kebutuhan khusus dapat diketahui serta diberikan intervensi dini bahasa bicara.

Metode : Kegiatan ini berupa memberikan pelatihan kepada guru-guru SLB Muhammadiyah Pauh IX Padang tentang teknik mengidentifikasi dan cara memberikan layanan yang akomodatif terhadapanak berkebutuhan khusus yang menggalami gangguan bahasa bicara.

Hasil : Dalam kegiatan ini wujud dari program pengabdian bagi masyarakat adalah tersosialisasikan kebutuhan intervensi dini bahasa bicara anak berkebutuhan khusus dan model-model layanan yang sesuai. Kesesuaian layanan bagi mereka yang kategori berkebutuhan khusus di sekolah luar biasa menunjukkan tercapainya akomodatif layanan. Data tentang angket yang tersebar bagi peserta dapat disimpulkan bahwa konsep tentang intervensi dini bahasa bicara anak berkebutuhan khusus ada pemahaman meningkat. Dan untuk program layanan akomodatif dan intervensi dini masih perlu ditingkatkan.

\footnotetext{
Abstract:

Background: The initial capital for handling patterns for children with special needs because it requires different preparations from normal children in general. Through early detection and early intervention of children's speech, the existence of different developmental patterns that lead to special needs can be identified and given early intervention in speech-language.

Methods: This activity is in the form of providing training to teachers of SLB Muhammadiyah Pauh IX Padang on identifying techniques and how to provide accommodating services for special needs who experience speech-language disorders.
} 
Result: In this activity, the form of community service
programs is to socialize the need for early intervention in
speech-language for children with special needs and
appropriate service models. The suitability of services for
those with special needs in special schools shows the
achievement of accommodative services. Data about
questionnaires that were distributed to participants, it can be
concluded that the concept of early intervention in the speech-
language of children with special needs has increased
understanding. And early intervention and accommodative
service programs still need to be improved.

\section{Pendahuluan}

Penerapan deteksi dan intervensi dini bahasa bicara untuk guru-guru sekolah luar biasa harus dimulai dengan adanya berbagai sosialisasi, maupun pelatihan. Deteksi dini dan intervensi dini bahasa bicara untuk anak usia dini berkebutuhan khusus sangat penting dilakukan baik oleh para guru. Melalui deteksi dini dan intervensi dini bahasa bicara anak-anak keberadaan tentang pola perkembangan yang berbeda dan mengarah pada kebutuhan khusus dapat diketahui serta dilayani sejak dini (Eaton Erika, 2012).. Hasil deteksi dini dan stimulasi dini digunakan sebagai modal awal pola penanganan untuk anak berkebutuhan khusus karena memerlukan persiapan yang berbeda dengan anak normal pada umumnya (Dockrell, Howell, Leung dan Fugard. 2017). Perbedaan tersebut terletak dalam aspek ketelitian dalam mengidentifikasi kekhususan mereka, kecermatan dalam melakukan asesmen berdasarkan kemampuan yang dimiliki anak berkebutuhan khusus.

Kondisi anak-anak berkebutuhan khusus memiliki berbagai macam klasifikasi, karakteristik yang sangat heterogen sehingga sangat diperlukan proses identifikasi atau asesmen untuk memenuhi kebutuhan mereka. Selain proses identifikasi yang cermat perlu adanya pemahaman konsep anak berkebutuhan khusus, kesadaran menerima keberadaannya serta mengetahui model-model layanan pendidikan yang tepat bagi mereka. Guru diharapkan memiliki bekal pengetahuan, keterampilan dan sikap dalam penanganan yang akomodatif bagi mereka akan mudah dan efisien. Oleh karena ketepatan dalam mengidentifikasi permasalahan yang dialami oleh anak berkebutuhan khusus dapat membantu dalam memberikan penanganan yang tepat, atau bahkan dapat sebagai dasar dalam memberikan intervensi dini (earlyintervention) bahasa bicara.

Berdasarkan hasil pemetaan anak-anak berkebutuhan khusus di provinsi Sumatera Barat oleh kementerian pemberdayaan perempuan dan anak tahun 2011 menunjukkan persentase anak berkebutuhan khusus yang bersekolah berdasarkan kelompok umur 0-18 tahun di provinsi Sumatera Barat tahun 2011 yang paling sedikit kelompok 0-3,0 tahun sebanyak 5 anak (0\%) dan paling banyak kelompok 9,1-12,0 tahun sebanyak 1.657 anak (32\%) serta kelompok 12,1-15,0 tahun sebanyak 1.607 anak (32\%). Sedangkan kelompok 3,1-6 tahun sebanyak 209 anak (4\%), kelompok 6,1-9,0 tahun sebanyak 835 anak (16\%), dan kelompok 15,1-18,0 tahun sebanyak 809 anak (16\%). 


\section{Jurnal ABDI MERCUSUAR}

Persentase yang paling sedikit pada usia 0-3 tahun dengan 0\% dikarenakan masih banyak orang tua yang belum menyadari pentingnya intervensi dini bahasa bicara dalam penanganan anak berkebutuhan khusus, adanya pendapat sebagian orangtua dengan usia 0-3 tahun belum menunjukkan adanya keterlambatan perkembangan, belum banyak layanan intervensi dini yang merata di seluruh provinsi Sumatera Barat.

Sejalan dengan permasalahan itulah maka perlu dilakukan kegiatan pengabdian kepada masyarakat yang dilaksanakan dengan sasaran pada para guru, dalam rangka memfasilitasi pendidikan anak pada umumnya dan anak berkebutuhan khusus. Kegiatan ini juga bertujuan agar para orangtua dan guru mampu melakukan identifikasi terhadap permasalahan anak berkebutuhan khusus. Ketepatan dalam melakukan identifikasi akan berakibat ketepatan dalam memberikan layanan bagi mereka.

\section{Metode Pelaksanaan}

Tempat dan Waktu kegiatan pengabdian pada masyarakat dilaksanakan di SLB Muhammadiyah Pauh IX Padang dilakukan 3 kali pertemuan, kelompok sasaran adalah guru-gurusebanyak 16 orang guru. Pelatihan ini dilakukan melalui model transfer ilmu atau penyampaian materi, diskusi dan praktek langsung yang di dampingi oleh tenaga ahli bidang terapi wicara. Kegiatan ini dilakukan dua tahap, pertama yaitu pemberian materi dan pelatihan kedua adalah praktek langsung yang di lakukan oleh guru dan diversifikasi oleh terapi wicara. Indikator keberhasilan pengabdian pada masyarakat dapat dilihat dari adanya peningkatan pemahaman guru dalam intervensi dini (earlyintervention) bahasa bicara anak berkebutuhan khusus. Setelah pelaksanaan kegiatan, guru yang sudah paham dan mahir dalam melakukan intervensi dini (earlyintervention) bahasa bicara pada anak berkebutuhan khusus diharapkan dapat mensosialisasikan dan mengajarkan kepada guru sekolah luar biasa yang lain.

\section{Hasil}

Intervensi yang dilakukan guru di sekolah lebih menitikberatkan dengan kegiatan yang tidak bisa dilakukan di rumah. Intervensi model ini merupakan model intervensi yang paling tepat bagi anak, khususnya anak berkebutuhan khusus, karena guru lebih mengenal dan memiliki kemampuan dalam mengenali hambatan anak melalui asesmen (Dockrell et al., 2017). Pada pelaksanaannya yang pertama dilakukan adalah melakukan pendekatan-pendekatan kepada anak yang tujuannya untuk menggali kemampuan serta hambatan yang dimiliki anak. Seperti yang terjadi pada kasus-kasus yang sering muncul masalah gangguan Bahasa bicara pada anak berkebutuhan khusus. Selanjutnya guru melakukan konseling dengan keluarga dan wawancara dengan keluarga. Tujuannya mendapat gambaran tentang kegiatan anak serta potensi yang ada didalam diri anak yang belum di dapatkan oleh guru. Setelah data dikumpulkan barulah guru memberikan simpulan gangguan/ masalah bahasa bicara yang terjadi pada ajak.

Dari hasil yang diperoleh guru bisa memberikan solusi kepada orangtua untuk membawa anak ke terapis wicara. Sedangkan untuk program di sekolah guru bisa 
menyesuaikan dengan kurikulum pembelajaran kelas. Misalnya guru bisa menanyakan langsung kepada orangtua setiap minggunya program apa saja yang sudah didapatkan anak di terapisnya. Guru bisa membuat pelajaran yang terkoneksi langsung dengan terapi yang diberikan oleh terapisnya. Sehingga antara program yang diberikan oleh terapis, guru dan orangtua bisa sejalan dan optimal.

Fungsi guru-guru dalam pemberian intervensi masalah Bahasa/bicara adalah menemukenali/mendeksi dini anak yang mengalami masalah Bahasa/bicara (American Speech-Language-Hearing Association., 2008; Dockrell et al 2017). Hal ini biasanya menjadi luput perhatian dari orangtua. Orangtua menilai jika semua layanan sudah diterima di sekolah. Padahal ada beberapa layanan yang memerlukan tenaga lain untuk melaksanakannya. Seperti dokter, terapis, psikolog ataupun tenaga lainnya. Sehingga guru juga sebagai pusat informasi orangtua.

Dari hasil pelatihan ini guru-guru bisa menjadi sumber informasi oleh orangtua terhadap langkah apa yang harus dilakukan orangtua jika anaknya mengalami masalah Bahasa/ bicara. Selain itu disekolah guru bisa melihat perubahan-perubahan terhadap anak ketika anak sudah mendapatkan terapis dan membuat program yang sesuai dengan kemampuan anak di akademiknya. Guru sebagai sumber informasi bagi orangtua tentunya juga sebagai modeling anak di sekolah. Sebelum pengalih tanganan orangtua di rumah, guru memberikan arahan dan bimbingan terlebih dahulu kepada orangtua terkait program yang dilakukan dri rumah. Kemudian, guru sebagai tempat konsultasi/ jembatan orangtua untuk mendapatkan saran terkait terapi apa yang akan diberikan kepada anak. Jadi ketika program diberikan dirumah/ pengalihtangan kepada orangtua bisa berjalan dengan optimal. Karna orangtua/keluarga dari segi waktu adalah orang yang paling banyak melakukan aktivitas di rumah bersama anak.

\section{Diskusi}

Layanan untuk anak bekebutuhan khusus beragam salah satunya adalah intervensi (Tan E.H.F \& Zhooriyati Sehu Mohamad 2019). Intervensi merujuk pada layanan tambahan atau modifikasi, strategi, teknik, atau bahan yang diperlukan untuk merubah perkembangan yang terhambat (sunardi dan sunaryo 2007). Selanjutnya Conrad dan Novick (Sunardi, 2012) menegaskan bahwa intervensi dini merupakan pogram pencegahan untuk mereduksi pengaruh-pengaruh negatif dari kelainan yang menyertai dan untuk memberikan kesempatan yang luas bagi tercapainya perkembangan yang sehat dan optimal. Intervensi menjadi sangat dibutuhkan ketika masalah/gangguan pada anak bisa di atasi dari sedini mungkin (Tan E.H.F \& Zhooriyati Sehu Mohamad 2019). Peran guru dalam intervensi tidak hanya di sekolah saja, guru sebagai tempat informasi oleh orangtua tentang anaknya. Selain itu guru bisa mendeteksi gangguan/masalah yang terjadi pada anak dan menyampaikan kepada orangtua.

Intervensi adalah layanan terhadap anak yang mengalami resiko hambatan perkembangan dalam aspek motorik, komunikasi dan bahasa, sosial emosi, kognisi, dan persepsi sensori (Olswang, Rodriguez dan Timler, 1998). Intervensi dimaksudkan untuk menetapkan cara-cara apakah yang patut dipergunakan untuk merencanakan perbaikan 


\section{Jurnal ABDI MERCUSUAR}

berdasarkan masalah yang ditemukan dalam proses diagnosa dan pemberian umpan balik. Intervensi diartikan segala langkah dan tindakan yang lebih baik dari cara-cara yang bersifat konvensional, sehingga kadang-kadang hanya tampak sebagai prinsipprinsip umum yang berlaku dalam berbagai situasi. Interveni dapat memperbaiki masalah-masalah perkembangan yang ada dan mengantisipasi.

Intervensi bisa dilakukan bila telah diadakan identifikasi, ada beragam cara yang dapat dilakukan untuk membantu anak dalam mengoptimalkan kemampuan berbicaranya, salah satunya melalui terapi wicara. Terapis wicara melakukan terapi pada masalah di bidang gangguan bahasa, gangguan bicara, gangguan suara, gangguan irama/kelancaran, gangguan menelan. Cohen, Nadel, \& Madnick (2002) mengungkapkan, jika pemberian intervensi sebaiknya dilakukan secara individu, seperti yang diungkapkannya "...because there is no one communication profile, there is no one treatment plan. Treatment should be individually designed to meet all of the communication needs of the child." Pemberian treatmen ataupun intervensi secara individu akan lebih fokus pada perkembangan anak. Program yang dirancang secara individu itu akan menyesuaikan dengan perkembangan, kemampuan dan kebutuhan anak, karena perkembangan serta kemampuan pada setiap anak akan berbeda-beda maka diperlukan pendekatan dan program yang berbeda pula.

Penanganan dan layanan anak berkebutuhan khusus dilakukan terapi wicara untuk menangani anak dengan gangguan komunikasi hal ini sering dideteksi terlambat bicara. Untuk itu diperlukan terapi wicara dengan melatih wicara anak agar anak dapat berkomunikasi dengan masyarakat. Terapi ini untuk melatih anak terampil mempergunakan sistem encoding berupa kemampuan mempergunakan organ untuk bicara, menggerakkan lengan tangan dan tubuh yang lain, serta ekspresi wajah. Sedangkan dalam pengetahuan anak diharapkan mampu mengerti tentang cara mengucapkan seluruh bunyi bahasa dengan benar, mengevaluasi bicaranya sendiri berdasarkan pengamatan visual, auditori, dan kinestetis. Sementara untuk sikap diharapkan anak berperilaku baik terhadap orang lain sehingga emosi anak berkembang seimbang.

Berkaitan dengan intervensi masalah gangguan bahasa pada anak berkebutuhan khusus guru juga memiliki perannya sendiri. Dalam banyak kasus orangtua menyerahkan semua perkembangan anaknya kepada guru. Saat terajdinya gangguan Bahasa orangtua tidak menyadari jika dilakukan deteksi dini bukan tidak mungkin masalah Bahasa/bicara anak bisa diatasi. Meurut Ann P (2007) "Yet many familiesarelikely to be so focused on their child'sneeds that they have not had the opportunitytoreflect broadly on what would be helpfulto them". Orangtua memberikan semua kebutuhan anak tanpa tahu cara merealisasikannya. Hal ini terjadi dikarenakan kurangnya pengetahuan dan kesadaran orangtua. Guru di sekolah bertugas menyampaikan informasi kepada orangtua dan menjelaskan langkah apa saja yang harus diambil orangtua terkait anak. Guru sebagai agen dalam penerapan intervensi ini di sekolah harus mengetahui ciri dan karakteristik anak yang mengalami gangguan/masalah bahasa bicara. Intervensi dini yang dilakukan guru lebih menitik beratkan sebagai bentuk dukungan dan layanan secara dini bagi anak yang beresiko 


\section{Jurnal ABDI MERCUSUAR}

Vol. 01, No. 01, Mei, 2021, pp. 061 - 067

mengalai masalah dalam Bahasa bicara. Intervensi dini penting karena, semakin dini intervensi maka gangguan dan masalah pada anak akan diatasi lebih optimal (Eaton Erika, 2012). Henningham H.B, \& Florencia Lopez Boo (2010) Intervensi dini bertujuan untuk mencapai perkembangan anak yang optimal (Optimum Child Development).

\section{Kesimpulan dan Saran}

Intervensi pada anak adalah salah satu upaya yang dilakukan untuk menemukenali sedini mungkin gangguan/masalah pada anak. Sehingga masalah atau gangguan tersebut bisa dicarikan solusinya dan di atasi dari dini. Guru sebagai salah satu tenaga untuk menemukenali masalah dan gangguan pada anak dalam hal ini masalah Bahasa bicara. Guru sebagi tempat informasi bagi orangtua dalam pemberian terapi apa saja yang memungkinkan diterima oleh anak. Hasil dari pengabdian ini diharakan guru lebih siap dalam menyikapi masalah-masalah Bahasa dan bicara pada anak berkebutuhan khusus. Selain itu guru mempunyai pengetahuan-pengetahuan dalam mendeteksi masalah gangguan Bahasa bicara pada anak berkebutuhan khusus di sekolah.

\section{Ucapan Terimakasih}

Pelaksanaan kegiatan ini tidak lepas dari bantuan dan dukungan dari berbagai pihak. Pada kesempatan ini kami mengucapkan terima kasih kepada Bapak Ketua Yayasan MERCUBAKTIJAYA dan ibu Ketua STIKes MERCUBAKTIJAYA Padang, Kepala LP2M dan Pimpinan Klinik MERCUBAKTIJAYA yang telah membantu memfasilitasi pelaksanaan kegiatan pengabdian ini.

\section{Daftar Referensi}

American Speech-Language-Hearing Association. (2008). Roles and Responsibilities of Speech-Language Pathologists in Early Intervention: Guidelines [Guidelines]. Available from www.asha.org/policy.

Ann P. Trunbull, Jean Ann Summers, Rud Turnbull. (2007). Family Supports and Services in EarlyIntervention: A Bold Vision. Journal of Early InterventionVol. 29, No. 3, 187-206

Cohen, W. I., Nadel, L., \& Madnick, M. E. (2002). Down Syndrome Visions for the 21st Century. New York: Wiley-Liss, Inc.

Dockrell, Howell, Leung and Fugard. (2017). Children with Speech Language and Communication Needs in England: Challenges for Practice. Front. Educ. https://doi.org/10.3389/feduc.2017.00035

Olswang, Rodriguez dan Timler. (1998). Recommending Intervention for Toddlers With Specific Language Learning DifficultiesWe May Not Have All the Answers, But We Know a Lot. American Journal of Speech-Language Pathology 7(1):23 DOI: 10.1044/1058-0360.0701.23

Sunardi dan Sunaryo. (2007). Intervensi Dini Anak Berkebutuhan Khusus. Jakarta : DIRJEN DIKTI.

Sunardi. (2012). Model Pendekatan Konseling Keluarga Untuk Intervensi Dini Anak Berkebutuhan Khusus. Prosidining pada Seminar Internasional Pasca 


\section{Jurnal ABDI MERCUSUAR}

Vol. 01, No. 01, Mei, 2021, pp. 061 - 067

Siswazah Pendidikan Khas UKM - UPI. Bangi. Fakulti Pendidikan UKM. 2012. Hal 302-316.

Tan E.H.F, Zhooriyati Sehu Mohamad. (2019). Early Intervention Services for Special Needs Children: An Exploration of the Effectiveness of Early Special Education in Malaysia, Psychological Research and Intervention, 2(1), 11-20. 